\title{
HUBUNGAN ANTARA PENGALAMAN PRAKTIK KERJA INDUSTRI DAN PRESTASI BELAJAR DENGAN KESIAPAN KERJA SISWA KELAS XI TEKNIK INSTALASI TENAGA LISTRIK SMK NEGERI 5 JAKARTA
}

\author{
${ }^{1}$ Qori Imamah, ${ }^{2}$ Soeprijanto, ${ }^{3}$ Imam Arif R. \\ ${ }^{1,2,3}$ Pendidikan Teknik Elektro, Fakultas Teknik, Universitas Negeri Jakarta \\ ${ }^{1,2,3}$ Email: qoriimamah009@gmail.com ; soeprijanto@unj.ac.id ; imam_ar@unj.ac.id
}

\begin{abstract}
The Relationship Between Experiences of Industrial Work Practices and Learning Achievement with Work Readiness of Greade XI Students of Electrical Power Installation Techniques in SMK Negeri 5 Jakarta. The research method used in this study uses a survey method with a correlational approach. The population in the study were 55 students of class X Electric Power Installation Engineering.The results showed that the hypothesis test with a significance level of 5\% showed that: (1) there was a positive and significant relationship between the experience of industrial work practices with work readiness, the results of tcount test (3.02)> ttable (2.00) with a contribution of 14.64\%; (2) there is a positive and significant relationship between learning achievement and student work readiness, test results of tcount (2.16)> ttable (2.00) with a contribution of 8,45\%; (3) there is a positive and significant relationship between industry work practice experience and learning achievement with student work readiness, the results of tcount (4,92.92)> ttable (3.16) with a contribution of $15.20 \%$.
\end{abstract}

Keywords: Experiences of Industrial Work Practices, Learning Achievement, Work Readiness

Abstrak
.Penelitian ini bertujuan untuk mengetahui hubungan antara pengalaman praktik kerja industri dan prestasi belajar dengan kesiapan kerja siswa kelas XI teknik instalasi tenaga listrik SMK Negeri 5 Jakarta. Metode penelitian yang digunakan pada penelitian ini menggunakan metode surve dengan pendekatan korelasiponal. Populasi dalam penelitian adalah siswa kelas X Teknik Instalasi Tenaga Listrik sebanyak 55 siswa. Hasil penelitian menunjukan bahwa uji hipotesis dengan taraf signifikansi 5\% menunjukan bahwa: (1) terdapat hubungan yang positif dan signifikan antara pengalaman praktik kerja industri dengan kesiapan kerja, hasil pengujian $t_{\text {hitung }}(3,02)>t_{\text {tabel }}(2,00)$ dengan kontribusi sebesar 14,64\%; (2) terdapat hubungan yang positif dan signifikan antara prestasi belajar dengan hasil belajar rangkaian listrik, hasil pengujian $t_{\text {hitung }}(2,16)>t_{\text {tabel }}$ $(2,00)$ dengan kontribusi sebesar 8,45\%; (3) terdapat hubungan yang positif dan signifikan antara pengalalam praktik kerja industri dan prestasi belajar dengankesiapan kerja siswa, hasil pengujian $\mathrm{t}_{\text {hitung }}(4,92)>\mathrm{t}_{\text {tabel }}(3,16)$ dengan kontribusi sebesar 15,20\%;

Kata kunci:Pengalaman Praktik Kerja Industri, Prestasi Belajar, Kesiapan Kerja Siswa

\section{PENDAHULUAN}

Menurut UU No. 13 tahun 2003 tentang ketenagakerjaan, kesiapan kerja atau kompetensi kerja adalah kemampuan kerja setiap individu yang mencangkup aspek pengetahuan, keterampilan dan sikap kerja yang sesuai dengan standar yang ditatapkan. Kesiapan kerja adalah keseluruhan kondisi individu yang meliputi kematangan fisik, metal dan pengalaman serta adanya kemauan dan kemampuan untuk melaksanakan suatu pekerjaan atau kegiatan.

${ }^{[1]}$ Menurut Kartono (2006: 191), kesiapan kerja adalah kemampuan seseorang untuk melaksanakan pekerjaan dengan baik di dalam maupun di luar hubungan kerja guna menghasilkan barang atau jasa.
${ }^{[2]}$ Menurut Ahim Surachim (2016:53) pendidikan system ganda sebagai alternative pola pembelajaran di SMK ditetapkan melalui Kemputusan Menteri Pendidikan dan Kebudayaan Indonesia Nomor 323/U/1997 (Pasal 1: ayat 1) "pendidikan system ganda adalah suatu bentuk penyelenggaraan pendidikan keahlian kejuruan yang memadukan secara sistematik dan sinkron program pendidikan di sekolah menengah kejuruan dengan program penguasaan keahlian yang diperoleh melalui bekerja langsung pada pekerjaan sesungguhnya di institusi psangan, terarah untuk mencapai suatu tingkat keahlian professional tertentu". 2

${ }^{[3]}$ Prsetasi belajar yang tinggi tidak terlepas dari apa yang mempengaruhi seorang 
siswa. Seperti yang diungkap oleh Ahmadi dan Supriyono dalam Beatrix Latifa (2018:8) bahwa prestasi belajar seorang individu merupakan hasil intreaksi antar berbagai faktor yang mempengaruhu baik dari dalam diri (faktor internal) maupun faktor dari luar diri (faktor eksternal).

Dalam hal ini, ketika dilakukan pada saat observasi awal, siswa yang memilih bekerja setelah lulus atas dasar beberapa kondisi. Kondisi pertama, sesuai tujuan awal masuk SMK untuk bekerja setelah lulus setidaknya dengan bekal keahlian tertentu, disamping atas motif membantu perekonomian keluarga, serta kesadaran untuk hidup mandiri. Kondisi kedua, siap bekerja atas dasar keinginan untuk melanjutkan. Uji Linieritas pendidikan namun terkendala biaya kuliah. Kondisi ketiga adalah siap bekerja untuk menyeimbangkan pengalaman kerja dan ilmu pengetahuan, sehingga berencana bekerja sambil mengikuti program kuliah kelas karyawan.

\section{METODE PENELETIAN}

${ }^{[4]}$ Menurut Sugiyono (2011 : 215), populasi adalah wilayah generalisasi yang terdiri atas obyek/subyek yang mempunyai kualitas dan karakteristik tertentu yang ditetapkan oleh peneliti untuk dipelajari dan kemudian ditarik kesimpulannya.

Pada penelitian ini, yang termasuk ke dalam populasi adalah seluruh siswa kelas XI Teknik Instalasi Tenaga Listrik SMK Negeri 5 Jakarta yang berjumlah 55 siswa.

Teknik pengumpulan data yang digunakan menggunakan data primer dan data sejunder. Data primer berupa kuesioner (angket) sedangkan data primer dari data nilai rapot dan nilai PKL siswa, kemudian tahapan analisis penelitian yaitu normalitas, liniearitas, uji hipotesis $\mathrm{X}_{1}$ dengan $\mathrm{Y}, \mathrm{X}_{2}$ dengan $\mathrm{Y}$ dan $\mathrm{X}_{1} \mathrm{X}_{2}$ dengan $\mathrm{Y}$, menggunakan koefisien korelasi, uji signifikasi koefisien korelasi, analisis regresi linier sederhana dan determinasi.

\section{HASIL DAN PEMBAHASAN Hasil Normalitas}

Tabel 1. Hasil Normalitas

\begin{tabular}{llll}
\hline No. Variabel & $\left(\mathrm{x}^{2}\right)$ & $\left(\mathrm{x}^{2}\right)$ & Keterangan \\
& hitung & tabel &
\end{tabular}

\begin{tabular}{lllrl}
\hline 1. & $\begin{array}{l}\text { Pengalaman } \\
\text { PKL }\left(\mathrm{X}_{1}\right)\end{array}$ & 9,84 & 12,6 & Normal \\
2. & $\begin{array}{l}\text { Prestasi } \\
\text { Belajar }\left(\mathrm{X}_{2}\right)\end{array}$ & 7,83 & 12,6 & Normal \\
3. & $\begin{array}{l}\text { Kesiapan } \\
\text { Kerja (Y) }\end{array}$ & 11,8 & 12,6 & Normal \\
\hline
\end{tabular}

Berdasarkan keterangan diatas untuk variabel pengalaman PKL, $\quad \chi^{2}$ hitung $=9,84$, sedangkan $\chi_{\text {tabel }}^{2}=12,6$ yang artinya $\chi^{2}$ hitung $\leq$

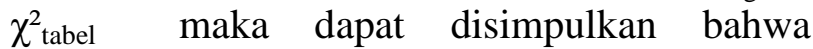
penyebaran data pada variabel pengalaman PKL berdistribusi normal.

Untuk variabel prestasi belajar, $\chi^{2}$ hitung $=7,83$ , dan $\chi_{\text {tabel }}^{2}=12,6$ yang artinya $\chi_{\text {hitung }}^{2} \leq \chi_{\text {tabel }}^{2}$ maka dapat disimpulkan bahwa penyebaran data pada variabel prestasi belajar siswa berdistribusi normal.

Untuk variabel kesiapan kerja , $\chi^{2}$ hitung= 11,8 , sedangkan $\chi^{2}$ tabel $=12,6$ yang artinya $\chi^{2}$ hitung $\leq \chi_{\text {tabel }}^{2}$ maka dapa t disimpulkan bahwa penyebaran data pada variabel kesiapan kerja berdistribusi normal. Maka, dari ketiga variabel yang diuji berdistribusi normal.

\section{Uji Linieritas}

Tabel 2. Hasil Liniearitas

\begin{tabular}{lllll}
\hline No & Variabel & $\begin{array}{l}\mathbf{F}_{\text {hitun }} \\
\text {. }\end{array}$ & $\mathbf{F}_{\text {tabel }}$ & $\begin{array}{l}\text { Keteranga } \\
\mathbf{n}\end{array}$ \\
\hline 1. & $\begin{array}{l}\text { Pengalama } \\
\text { n PKL (X) }\end{array}$ & 0,878 & 2,08 & Linear \\
& & 4 & \\
& $\begin{array}{l}\text { dengan } \\
\text { Kesiapan }\end{array}$ & & & \\
Kerja (Y) & & & \\
2. & $\begin{array}{l}\text { Prestasi } \\
\text { Belajar }\end{array}$ & 1,27 & 1,92 & Linear \\
& & 1 & \\
$\left(\mathrm{X}_{2}\right)$ & & & \\
dengan & & & \\
& Kesiapan \\
Kerja (Y & & & \\
\hline
\end{tabular}

Berdasarkan keterangan hasil perhitungan untuk variabel pengalaman PKL dengan kesiapan kerja siswa menunjukan $\mathrm{f}_{\text {hitung }}<\mathrm{f}_{\text {tabel }}$ $(0,878<2,084)$, sedangkan untuk hasil perhitungan antara prestasi belajar dengan kesiapan kerja siswa menunjukan $\mathrm{f}_{\text {hitung }}<\mathrm{f}_{\text {tabel }}$ $(1,27<1,921)$.Hasil ini berati Ho diterima sehingga model regresi linier. 
Hubungan Antara Pengalaman Praktik Kerja Industri dengan Kesiapan Kerja Siswa.

Berdasarkan hasil perhitungan product moment, diperoleh $\mathrm{r}_{\text {hitung }}=0,383>$ dari $\mathrm{r}_{\text {tabel }}=0,259$, dengan demikian Ho ditolak karena $r_{\text {hitung }}$ lebih besar dari $r_{\text {tabel }}$ sehingga regresi yang diperoleh adalah berarti. Berdasarkan hasil perhitungan uji-t didapatkan $\mathrm{t}_{\text {hitung }}\left(3,02>\mathrm{t}_{\text {tabel }}(2,00)\right.$ maka $\mathrm{H}_{\mathrm{o}}$ diterima sehingga dapat disimpulkan terdapat hubungan yang signifikan antara pengalaman praktik kerja industri dengan kesiapan kerja. Hasil pengujian menunjukkan bahwa koefisien determinasi $\mathrm{Y} \mathrm{KD}=\mathrm{r}_{\mathrm{xy}}{ }^{2} \mathrm{x} 100 \%=(0,1464)^{2} \mathrm{x}$ $100 \%=14,64 \%\left(r^{2}\right)$ sebesar $14,64 \%$ dapat disimpulkan bahwa kontribusi kesispan kerja siswa ditentukan oleh pengalaman praktik kerja industri sebesar $14,64 \%$ dan sisanya $85,36 \%$ ditentukan oleh variabel lain. Analisis regresi linier sederhana terhadap pasangan data penelitian antara praktik kerja industri dengan kesiapan kerja menghasilkan koefisien regresi (b) sebesar 0,833 dan konstanta (a) sebesar 3,07. Dari perhitungan, persamaan regresi yang digunakan untuk memprediksi kesiapan kerja berdasarkan kemandirian belajar adalah $\hat{\mathrm{Y}}=3,07+0,833 \mathrm{X}_{1}$.

Gambar 1. $X_{1}$ dengan $Y$

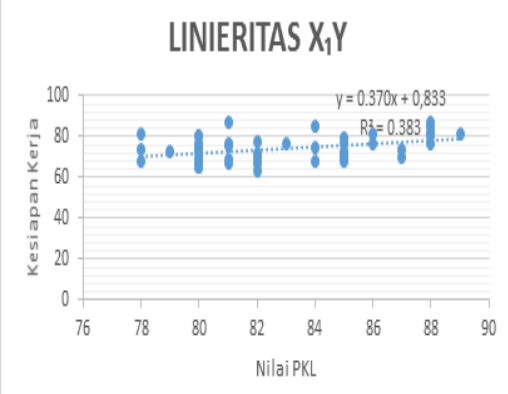

Berdasarkan hasil pengujian mengatakan bahwa terdapat hubungan yang signifikan yaitu Analisis Hubungan Antara Pengalaman Praktik Kerja Industri dengan Kesiapan Kerja Siswa.

\section{Analisis Hubungan Antara Prestasi Belajar dengan Kesiapan Kerja Siswa.}

Berdasarkan hasil perhitungan product moment , diperoleh $\mathrm{r}_{\text {hitung }}=0,91>$ dari $\mathrm{r}_{\text {tabel }}=0,259$, dengan demikian Ho ditolak

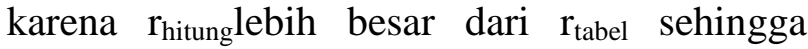
regresi yang diperoleh adalah berarti. Berdasarkan hasil perhitungan didapatkan $t_{\text {hitung }} 2,16>t_{\text {tabel }}(2,00)$, maka $\mathrm{H}_{\mathrm{o}}$ diterima sehingga dapat disimpulkan terdapat hubungan yang signifikan antara prestasi belajar dengan kesiapan kerja. Koefisien determinasi berdasarkan acuan table korelasi data tersebut tergolong rendah terhadap variabel $\mathrm{X}_{2}$ terhadap variabel $\mathrm{Y}$ adalah $0,0845 \mathrm{KD}=\mathrm{r}_{\mathrm{x} 2 \mathrm{y}}{ }^{2} \mathrm{x} 100 \%=$ $(0,291)^{2}$ X $100 \%=8$. Hasil pengujian menunjukkan bahwa koefisien determinasi $\left(\mathrm{r}^{2}\right)$ sebesar $8,45 \%$ dapat disimpulkan bahwa kontribusi kesiapan kerja siswa ditentukan oleh prestasi belajar sebesar $8,45 \%$ dan sisanya 91,55\% ditentukan oleh variabel lain. Analisis regresi linier sederhana terhadap pasangan data penelitian antara prestasi belajar dengan kesiapan kerja siswa menghasilkan koefisien regresi (b) sebesar 0,086 dan konstanta (a) sebesar 3,13. Dari perhitungan, persamaan regresi yang digunakan untuk memprediksi hasil belajar berdasarkan sikap ilmiah adalah $\hat{\mathrm{Y}}=3,13+0,086 \mathrm{X}_{2}$.

Hasil penelitian ini menunjukan bahwa ada hubungan yang positif dan signifikan antara prestasi belajar dengan kesiapan kerja siswa. Jadi selain pengalaman praktik kerja industri, kesiapan kerja siswa juga dipengaruhi oleh prestasi belajar. Pengujian hipotesis kedua menyimpulkan bahwa terdapat hubungan positif dan signifikan antara prestasi belajar dengan kesiapan kerja siswa yang ditunjukan oleh nilai thitung sebesar 2,16 lebih besar dari $t_{\text {tabel }} 2,00$. Besarnya kontribusi variabel prestasi belajar terhadap kesiapan kerja pada penelitian ini sebesar $8,45 \%$.

Gambar 2. $X_{2}$ dengan $Y$ LINIERITAS $X_{2} Y$

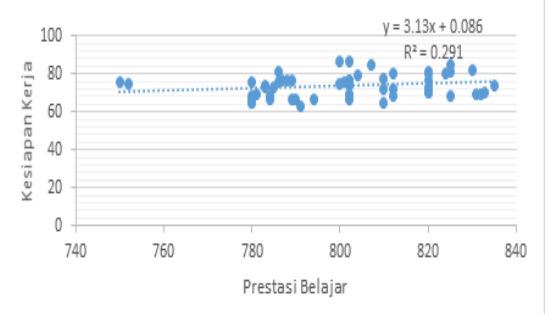


Berdasarkan hasil pengujian mengatakan bahwa terdapat hubungan yang signifikan yaitu Analisis Hubungan Antara Prestasi Belajar dengan Kesiapan Kerja Siswa.

\section{Analisis Hubungan Antara Pengalaman Praktik Kerja Industri dan Prestasi Belajar dengan Kesiapan Kerja Siswa.}

Berdasarkan hasil perhitungan product moment diperoleh $\mathrm{r}_{\text {hitung }}=0,390>$ dari $\mathrm{r}_{\text {tabel }}=0,259$, dengan demikian Ho ditolak karena $r_{\text {hitung }}$ lebih besar dari $r_{\text {tabel }}$ sehingga regresi yang diperoleh adalah berarti. Berdasarkan hasil perhitungan didapatkan $\mathrm{f}_{\text {hitung }} 4,92>\mathrm{f}_{\text {tabel }}(3,16)$, maka $\mathrm{H}_{\mathrm{o}}$ diterima sehingga dapat disimpulkan terdapat hubungan yang signifikan antara pengalaman praktik kerja industri dan prestasi belajar dengan kesiapan kerja siswa. $\mathrm{KD}=\mathrm{r}_{\mathrm{x} 1 \mathrm{x} 2 \mathrm{y}}{ }^{2} \times 100 \%=$ $\left(0,390^{2} \times 100 \%=15,20 \%\right.$. Hasil pengujian menunjukkan bahwa koefisien determinasi $\left(\mathrm{r}^{2}\right)$ sebesar $15,20 \%$ dapat disimpulkan bahwa kontribusi kesiapan kerja siswa ditentukan oleh pengalaman praktuk kerja industri dan prestasi belajar sebesar $15,20 \%$ dan sisanya $84,8 \%$ ditentukan oleh variabel lain. Analisis regresi linier berganda terhadap pasangan data penelitian antara pengalaman praktik kerja industri dan prestasi belajar dengan kesiapan kerja menghasilkan koefisien regresi (c) sebesar 0,047 dan (b) sebesar 0,459 serta konstanta (a) sebesar 0,069 Dari perhitungan, persamaan regresi yang digunakan untuk memprediksi kesiapab kerja berdasarkan pengalaman praktik kerja industri dan prestasi belajar siswa adalah $\hat{\mathrm{Y}}=0,069+$ $0,459 \mathrm{X}_{1}+0,047 \mathrm{X}_{2}$.

\section{KESIMPULAN DAN SARAN}

\section{KESIMPULAN}

Berdasarkan hasil penelitian dan pengolahan data yang telah dipaparkan pada bab-bab sebelumnya, maka dapat ditarik kesimpulan sebagai berikut:

1) Berdasarkan hasil pengujian hipotesis didapatkan nilai koefisien korelasi sebesar 0,383 dan $t_{\text {hitung }}(3,02)>t_{\text {tabel }}(2,00)$. Sehingga dapat disimpulkan bahwa terdapat hubungan yang positif dan signifikan antara pengalaman praktik kerja industry dengan kesiapan kerja siswa.

2) Berdasarkan hasil pengujian hipotesis didapatkan nilai koefisien korelasi sebesar 0,291 dan $t_{\text {hitung }}(2,16)>t_{\text {tabel }}(2,00)$. Sehingga dapat disimpulkan bahwa terdapat hubungan yang positif dan signifikan antara prestasi belajar dengan kesiapan kerja siswa.

3) Berdasarkan hasil pengujian hipotesis didapatkan nilai koefisien korelasi sebesar 0,390 dan Fhitung $(4,92)>$ Ftabel $(3,16)$. Sehingga dapat disimpulkan bahwa terdapat hubungan yang positif dan signifikan antara pengalaman praktik kerja industri dan prestasi belajar dengan kesiapan kerja siswa.

\section{SARAN}

1. Siswa diharapkan sadar akan pentingnya pengalaman praktik kerja industri dalam mencapai kesiapan kerja yang tinggi, sehingga siswa mampu mengatur dirinya dalam kesiapan bekerja pada saat di tempat siswa bekerja, kemudian selanjutnya melakukan evaluasi pada saat di praktik kerja industri serta adanya kesadaran untuk mampu bekerja sesuai dibidangnya tidak dimanapun bekerja.

2. Siswa juga harus bisa meningkatkan prestasi belajar didalam dirinya karena prestasi belajar juga berhubungan dengan kesiapan kerja siswa, hal ini berkaitan dengan seberapa kuat rasa ingin tahu, berpikit kritis, kreativitas, dan ketekunan siswa dalam mengikuti serta melaksanakan proses belajar agar kesiapan kerja bisa diimbangi dengan praktik..

3. Saran untuk guru yang mengajar lebih disiplin lagi kegiatan belajar mengajar, selanjutnya untuk nilai PKL jangan diabaikan sehingga siswa tersebur tidak merasa penting akan melaksanakan PKL tersebut dan untuk administrasi pemberkasan lebih ditingkatkan lagi kerapihan dan penyimpanan.

4. Saran untuk penelitian selanjutnya, penelitian lebih lanjut yang berkaitan dengan pengalaman praktik kerja industri, prestasi belajar dan kesiapan kerja, karena 
penelitian ini hanya berlangsung satu semester melalui pengisian kuesioner kepada 55 responden sehingga diharapkan peneliti selanjutnya dapat meningkatkan kualitas penelitian, baik dengan menggunakan instrumen yang lebih tepat ataupun melakukan pengotrolan secara berkala selama waktu yang ditentukan terhadap responden yang diteliti.

\section{DAFTAR PUSTAKA}

${ }^{[1]}$ Kartini, Kartono.2006. Menyiapkan dan Memandu Karir. Jakarta: Rajawali

${ }^{[2]}$ Surachim, Ahim. 2016. Efektifitas Pembelajaran: Pola Pendidikan Sistem Ganda. Bandung: Alfabeta.

${ }^{[3]}$ Latifa, Beatrix.2018. Hubungan antara Manajemen Waktu dan Keaktifan dalam Organisasi Kemahasiswaan Rumpun Teknik Elektro Fakults Teknik Universitas Negeri Jakarta. Skripsi. Jakarta: Fakultas Teknik. Universitas Negeri Jakarta.

${ }^{[4]}$ Sigiyono.2001. Metode Penelitian Kuantitatif, Kualitatif dan R\&D. Bandung:Alfabeta 